\title{
PENDAMPINGAN IMPLEMENTASI SISTEM PENCATATAN AKUNTANSI SEKOLAH BAGI DAN SMK NURUL HUDA KEPADANGAN KABUPATEN SIDOARJO
}

\author{
Sarwenda Biduri ${ }^{1}$, Akhmad Mulyadi ${ }^{2}$, Ilmi Usrotin Choiriyah ${ }^{3}$ \\ ${ }^{1,2,3}$ Fakultas Bisnis Hukum dan Ilmu Sosial, Universitas Muhammadiyah Sidoarjo \\ Email: sarwendabiduri@umsida.ac.id
}

\begin{abstract}
An educational institution requires good administrative management to serve the needs of the community. The use of Information Systems is a very significant investment at this time. With information that is very fast, accurate, effective and efficient. Payment of routine and non-routine operational administration is still manual where data is recorded in the recap book and excel manual, this is done by SMK Nurul Huda Tulangan and MAN Featured Tlasih, because the process can take time, and data storage is still in the form of archives. The purpose of this study was to determine the Design of School Accounting Systems that are currently running at SMK Nurul Huda Tulangan and MAN Unggulan Tlasih. While the usefulness of this research is to increase knowledge and insight in the field of information technology, especially relating to the Design of School Financial Accounting Systems. To overcome this problem a computerized information system needs to be made. The research method used is the method of observation analysis, interviews and literature and elicitation studies. The application program used is PHP (Personal Home Page Tools) and the database uses MySQL. The system built is expected to support student financial administration activities including payment of tuition fees, savings, re-registration, building money, national examinations, and other costs, making it easier to find the required student databases and in making monthly reports faster and more timely. The results of this program, namely the implementation of web-based school financial accounting applications, namely pocket.umsida.ac.idd easily by the two schools.
\end{abstract}

Keywords: Accounting Recording System, Web-Based School Accounting.

\begin{abstract}
Abstrak. Suatu lembaga pendidikan memerlukan pengelolaan administrasi yang baik untuk melayani kebutuhan masyarakat. Penggunaan Sistem Informasi merupakan sebuah investasi yang sangat signifikan pada saat ini. Dengan informasi yang sangat cepat, akurat, efektif dan efisien. Pembayaran administrasi operasional rutin dan non rutin masih bersifatmanual dimana pencatatan data dilakukan ke dalam buku rekap dan manual excel, hal ini yang dilakukan oleh SMK Nurul Huda Tulangan dan MAN Unggulan Tlasih, karena proses tersebut dapat menyita waktu, dan penyimpanan data masih berupa arsip. Adapun tujuan penelitian ini adalah untuk mengetahui Perancangan Sistem Akuntansi Sekolah yang sedang berjalan di SMK Nurul Huda Tulangan dan MAN Unggulan Tlasih. Sedangkan kegunaan dari penelitian ini adalah untuk menambah pengetahuan dan wawasan dibidang teknologi informasi khususnya yang berhubungan dengan Perancangan Sistem Akuntansi Keuangan Sekolah. Untuk mengatasi masalah tersebut perlu dibuat suatu sistem informasi yang terkomputerisasi. Metode penelitian yang digunakan adalah metode analisis observasi, wawancara dan studi pustaka dan elisitasi. Program aplikasi yang digunakan adalah PHP (Personal Home Page Tools) serta database menggunakan MySQL. Sistem yang dibangun diharapkan dapat mendukung kegiatan pembayaran administrasi keuangan siswa diantaranya pembayaran SPP, Tabungan, Daftar Ulang, Uang Gedung, Ujian Nasional, dan biaya lain-lain sehingga mempermudah dalam pencarian datasiswa yang diperlukan dan dalam hal pembuatan laporan bulanan menjadi lebih cepat dan tepat waktu. Hasil dari program ini, yaitu dapat diimplementasikannya aplikasi akuntansi keuanga sekolah berbasis web yaitu saku.umsida.ac.iddengan mudah oleh kedua sekolah tersebut.
\end{abstract}

Kata Kunci: Sistem Pencatatan Akuntansi,Akuntansi Sekolah Berbasis Web.

\section{PENDAHULUAN}

Pada perkembangan teknologi industri 4.0 dan perkembangan teknologi yang semakin maju, sehingga dampaknya dapat kita lihat betapa kompleksnya persoalan-persoalan dalam kehidupan pendidikan, perkantoran dan dunia industri dapat diselesaikan dengan mudah karena adanya bantuan perangkat teknologi yang digunakan oleh instansi tersebut. Dunia pendidikan merupakan basis pertama yang harus di persiapkan secara kualitas dalam menghadapi tantangan di era 4.0 ini. Pendidikan merupakan investasi, dengan demikian agar pendidikan dapat tercapai sasaran yang diharapkan maka, diperlukan pengelolaan yang efektif dan efisien. Pengelolaan pembiayaan pendidikan meliputi 
pengaturan penerimaan, pengalokasian dan pertanggungjawaban keuangan sehingga dapat terwujudnya transparansi dan akuntabilitas. Berbagai cara yang dapat dilakukan oleh organisasi tersebut bertanggung jawab antara lain: membuat dokumentasi kegiatan, publikasi kegiatan, membuat catatan keuangan, dan menyerahkan laporan keuangan tepat waktu (Setiawati \& Diana, 2011). PSAK 45 merupakan standar yang tepat untuk diterapkan untuk yayasan pendidikan yang mana karakteristik usahanya tidak untuk mencari keuntungan. Jadi, PSAK 45 ini digunakan untuk Pelaporan Keuangan Entitas Nirlaba.

PSAK 45 menyebutkan bahwa karakteristik entitas nirlaba diantaranya, sumber daya diperoleh dari pemberi sumber daya yang tidak mengharapkan pembayaran kembali atau manfaat ekonomi yang sebanding dengan sumber daya yang diberikan, tidak ada kepemilikan, kebutuhan operasionalnya dari pendapatan jasa yang diberikan kepada publik. Adanya tuntutan transparansi dan akuntabilitas terhadap organisasi nirlaba akan menjadi beban bagi organisasi yang bersangkutan, terlebih lagi bagi organisasi yang telah mapan. SMK Nurul Huda Kepadangan Kabupaten Sidoarjo masih menggunakan sistem manual pada pencatatan keuangan sekolahnya, belum melakukan pembukuan yang baik untuk menyajikan laporan keuangan. Keterbatasan sumber daya yang ada menyebabkan laporan keuangan belum tersedia, bahkan pencatatan masih terbatas perekapan manual saja. Proses perekapan secara manual dilakukan jika ada pemasukan pembayaranpembayaran dari siswa sekolah tersebut, tidak diposting lebih lanjut kembali karena SMK Nurul huda Kepadangan hanya sebatas merekap saja kemudian hasil rekapan tersebut akan diserahkan kepada yayasan dari sekolah tersebut. Keterbatasan lain yang dihadapi oleh SMK Nurul Huda ini yaitu masih sangat minimnya fasilitas penunjang untuk mendukung proses perekapan tersebut sehingga berdampak pada penyusunan laporan keuangan untuk publik yang belum dilakukan. Sekolah ini bahkan hanya memiliki 1 komputer untuk menunjang proses pencatatan akuntansi, karena itu mereka membutuhkan bantuan bagaimana cara memproses laporan keuangan dengan bantuan komputer dengan program excel secara sederhana.

Komponen keuangan sekolah merupakan komponen produksi yang menentukan terlaksananya kegiatan belajar-mengajar bersama komponen-komponen lain. Dengan kata lain, setiap kegiatan yang dilakukan sekolah memerlukan biaya, dalam tataran pengelolaan(Costa., 2000). Dalam kegiatan abdimas di SMK Nurul Huda ini, membantu dengan pendampingan pencatatan akuntansi yang sesuai dengan standar organisasi nirlaba. Target luaran dari kegiatan ini yaitu dapat terciptanya pengelolaan keuangan sekolah secara menyeluruh, yaitu perencanaan, pelaksanaan, penatausahaan, pelaporan, pertanggungjawaban, dan pengawasan keuangan sekolah.

\section{METODE PELAKSANAAN}

Metode pelaksanaan kegiatan menjelaskan tahapan atau langkah-langkah dalam melaksanakan solusi yang ditawarkan untuk mengatasi permasalahan. Berdasarkan permasalahan yang dihadapi mitra maka salah satu solusi yang dapat dilakukan adalah membekali pengetahuan tentang pemrograman dan jaringan komputer dalam bentuk kegiatan pelatihan kepada bendahara sekolah. Seluruh kegiatan direncanakan dilaksanakan dalam waktu 8 (delapan) bulan, yang meliputi beberapa tahapan:

Persiapan Kelengkapan Kegiatan Dalam tahapan ini ada beberapa kegiatan yang dilakukan, di antaranya:

a. Mempersiapkan tempat pelaksanaan pelatihan, yaitu dengan mempersiapkan Komputer di sekolah mitra beserta peralatan penunjang sebagai peralatan utama dalam pelatihan tersebut.

b. Mempersiapkan alat dan bahan yang digunakan dalam pelatihan, yaitu aplikasi software keuangan sekolah dan perlengkapan jaringan (koneksi internet).

c. Mempersiapkan media presentasi interaktif yaitu slide presentasi yang dibuat oleh tim abdimasdan berkas pendukung lainnya (seperti laporaan keuangan sekolah yg manual)

d. Pembuatan aplikasi (saku.umsida.ac.id) khusus untuk sekolah yang dijadikan oleh obyek abdimas secara seerhana dan mudah untuk di pahami oleh Bendahara Sekolah.

\section{Pelaksanaan Pelatihan}

Dalam pelatihan ini, bendahara sekolah di mintai konfirmasi bagaimana proses pencatatan akuntansi yang biasanya mereka lakukan baik itu kegiatan rutin maupun non rutin, apa saja transaksi-transaksi operasional yang ada di sekolah-sekolah tersebut. Bendahara sekolah akan diberi pengetahuan mengenai bagaimana 
memahami akuntansi sekolah khususnya berbasis web, memahami akun-akun secara akuntansi yang akan diaplikasikan.

\section{Pelaksanaan Follow Up}

Satu minggu setelah pendampingan dilakukan peninjauan ke lokasi masing-masing sekolah untuk mengecek apakah progress pengembangan aplikasi dapat dilakukan di sekolah atau tidak. Di samping itu untuk mengkonfirmasi kendala yang dihadapi bendahara dalam pengimplementasian aplikasi. Metode Pendekatan yang ditawarkan untuk menyelesaikan persoalan mitra yang telah disepakati bersama adalah mengadakan pendampingan, sosialisasi, diskusi, dan tanya jawab, mengimplementasikan aplikasi serta pelatihan (workshop) pada masing-masing mitra. Pada kegiatan ini mitra memberikan partisipasi dalam bentuk: 1. mengkoordinir bendahara yang akan dilatih, 2. mempersiapkan tempat untuk sosialisasi dan workshop, 3. mempersiapkan dan memfasilitasi sarana prasarana yang dibutuhkan. Langkah evaluasi pelaksanaan program dan keberlanjutan program di lapangan.

\section{HASIL DAN PELAKSANAAN \\ Pelaksanaan Kegiatan}

Kegiatan pengabdian masyarakat ini diawali dengan persiapan pelaksanaan kegiatan, yaitu diantaranya observasi langsung terhadap objek, wawancara dengan objek dalam hal ini Bendahara SMK Nurul Huda dan MA Unggulan Tlasih. Observasi dilakukan dengan melihat keadaan obyek dan mewawancarai apa yng menjadi kelemahan di SMK Nurul Huda dan MA Unggulan Tlasih.
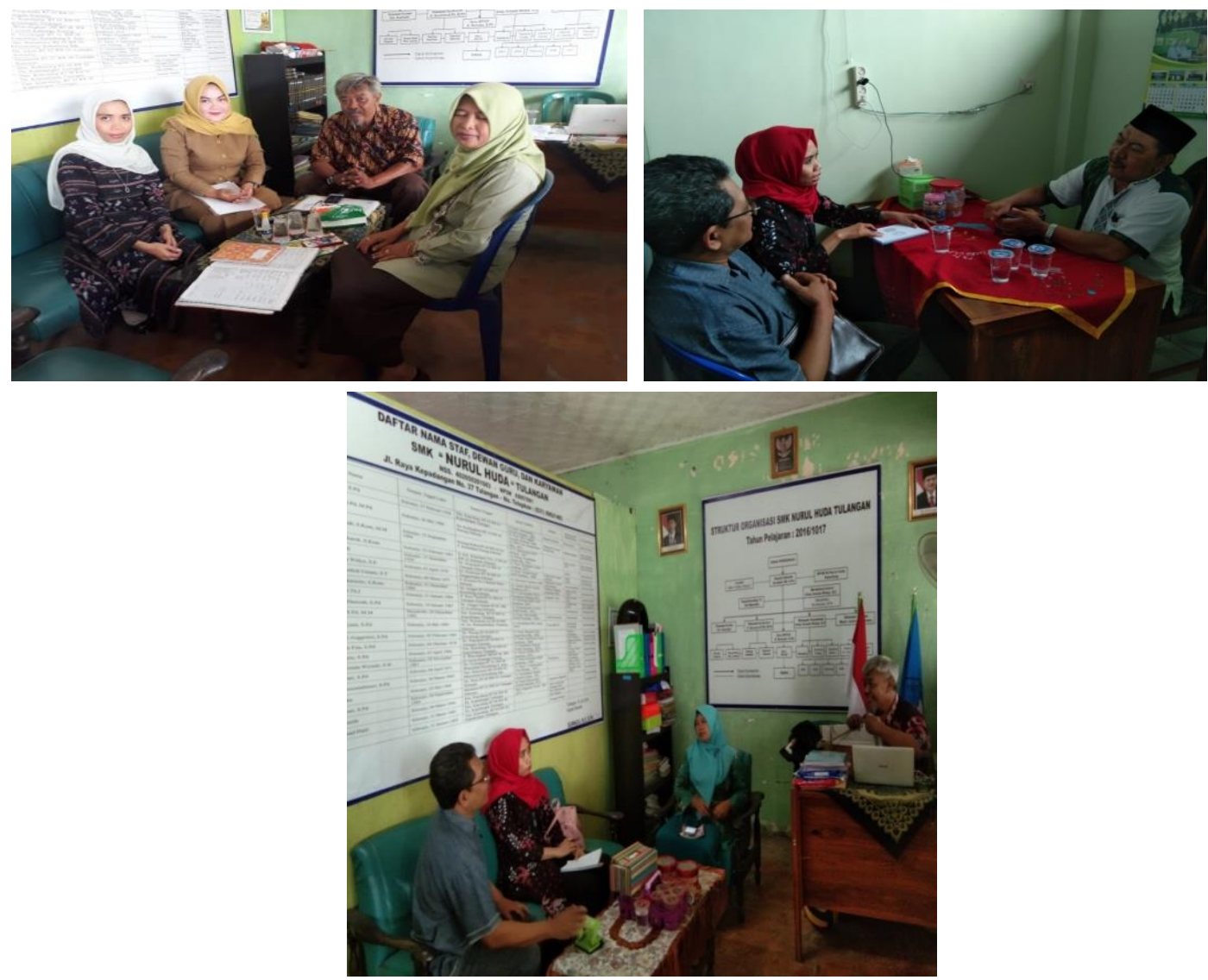

Gambar 1. Proses Observasi dan Wawancara

Pada pelaksanaan kegiatan ini, tim mengadakan pertemuan dengan pihak sekolah, yaitu kepala sekolah dan bendahara sekolah. Tim abdimas melakukan pengenalan bagimana sistem manajemen keuangan di SMK Nurul Huda Kepadangan, dan hasil yang didapat dilapangan bahwa sistem keuangan di sekolah tersebut dilakukan secara sentralisasi atau terpusat, jadi sistem pencatatan yang dilakukan semua terpusat, SMK Nurul Huda hanya melakukan perekapan pembayaran dari siswa setelah terkumpul kemudian di setorkan ke yayasan dari sekolah tersebut, sedangkan MA Unggulan Tlasih memiliki otonomi sendiri untuk mengatur 
keuangannya sendiri, namun kedua sekolah tersebut sama -sama masih menggunakan system manual. Sistem manual yang dilakukan oleh SMK Nurul Huda Kepadangan sangat sederhana sekali, semua pencatatan transaksi yang masuk di rekap dalam 1 buku, jika MA Unggulan Tlasih masih menggunakan program excel biasa. Dengan melihat kondisi tersebut, sebagai tim abdimas kami memberikan masukan-masukan yang sekiranya bermanfaat bagi sekolah tersebut yaitu:

a. Dapat mengenal dokumen bukti transaksi yang digunakan oleh organisasi, dalam hal ini khususnya sekolah baik jumlah fisik maupun jumlah rupiahnya, serta data-data penting yang kaitannya dengan transaksi organisasi atau sekolah

b. Dapat mengelompokkan dan mencatat data yang tercantum dalam dokumen bukti transaksi ke dalam catatan-catatan akuntansi meskipun itu untuk organisasi yang masih sederhana.

c. Dapat meringkas semua informasi-informasi yang tercantum dalam catatan-catatn akuntansi agar dapat menjadi laporan-laporan yang dapat digunakan baik pihak internal maupun eksternal.
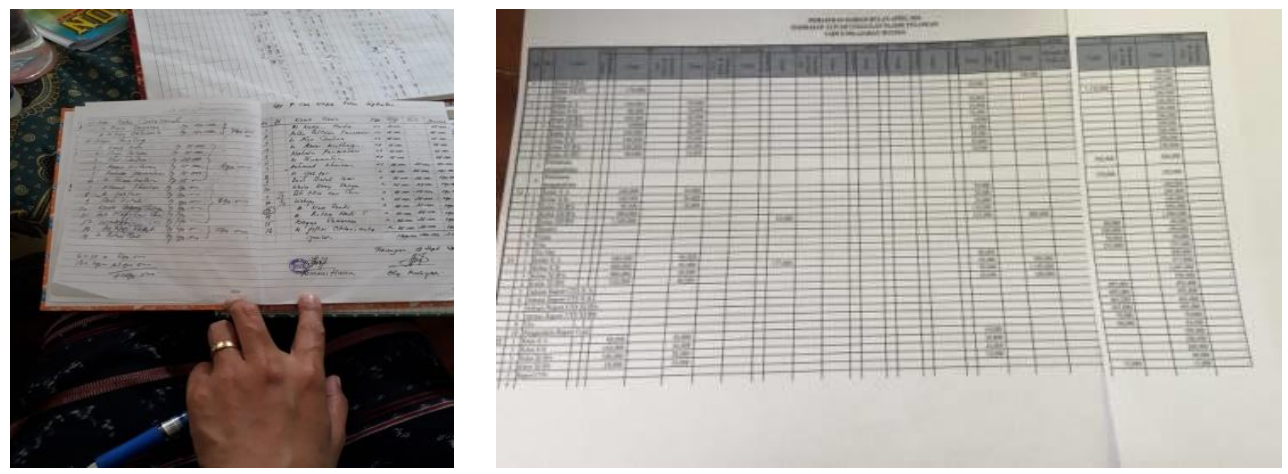

Gambar 2. Proses Pencatatan Manual

Pada proses pencatatan yang dilakukan secara sentralisasi atau terpusat, sekolah ini hanya melakukan perekapan kemudian di laporkan ke pihak yayasan, itu merupakan kegiatan rutin yang dilakukan oleh sekolah ini. Namun secara realitanya semua pencatatan keuangan ini masih dilakukan secara manual, karena terkendalanya fasilitas dan sumberdaya manusia. Kendala fasilitas terdapat pada masih kurangnya perangkat hardware maupun software yang dapat memudahkan proses akuntansi ini secara efektif. Desain sistem yang coba kami tawarkan demi membantu manajemen keuangan sekolah ini malalui penataan desain sistem, meskpun sistem yang dijalankan sentralisasi. sistem harus memiliki pengetahuan untuk membedakan sistem akuntansi dan metode pemrosesan data baik pemrosesan data secara manual maupun dengan menggunakan komputerisasi.

Kemampuan untuk membedakan pemrosesan transaksi secara manual dan komputer cukup penting, karena pada organisasi tertentu tidak semua transaksi dapat di proses dengan komputer dan kemampuan desainer sistem dalam mengevaluasi alternatif-alternatif yang dipertimbangkan pengetahuan akan prinsip- prinsip dasar sistem akuntansi. Singkatnya, prinsip dasar yang terkandung dalam sistem akuntansi yang baik kemungkinan besar sistem yang dirancang pada perusahaan / organisasi tertentu akan mengalami kesulitan ketika diterapkan.

Langkah terakhir yang kami lakukan adalah melakukan pendampingan secara langsung bagaimana aplikasi akuntansi sekolah khususnya akuntansi kas masuk dan keluar itu dapat di implementasikan. Aplikasi http://saku.umsida.ac.id adalah aplikasi akuntansi sederhana berbasis web dari aplikasi android yang dapat digunakan untuk mengelola keuangan sekolah. Aplikasi ini online dan dapat di akses dari mana saja, lewat PC Komputer maupun lewat Handphone. Akuntansi saku UMSIDA ini mudah digunakan karena tidak perlu belajar sulit-sulit untuk mencatat transaksi keuangan. Servernya menggunakan sever UMSIDA dan domainnya ikut domain UMSIDA. Dengan pendampingan yang kami lakukan, SMK Nurul Huda dan MA Unggulan Tlasih sangat terbantu dengan adanya aplikasi ini, diantaranya dapat menelusur jika terjadi penunggakan pembayaran, pekerjaan lebih efektif dan efisien. 

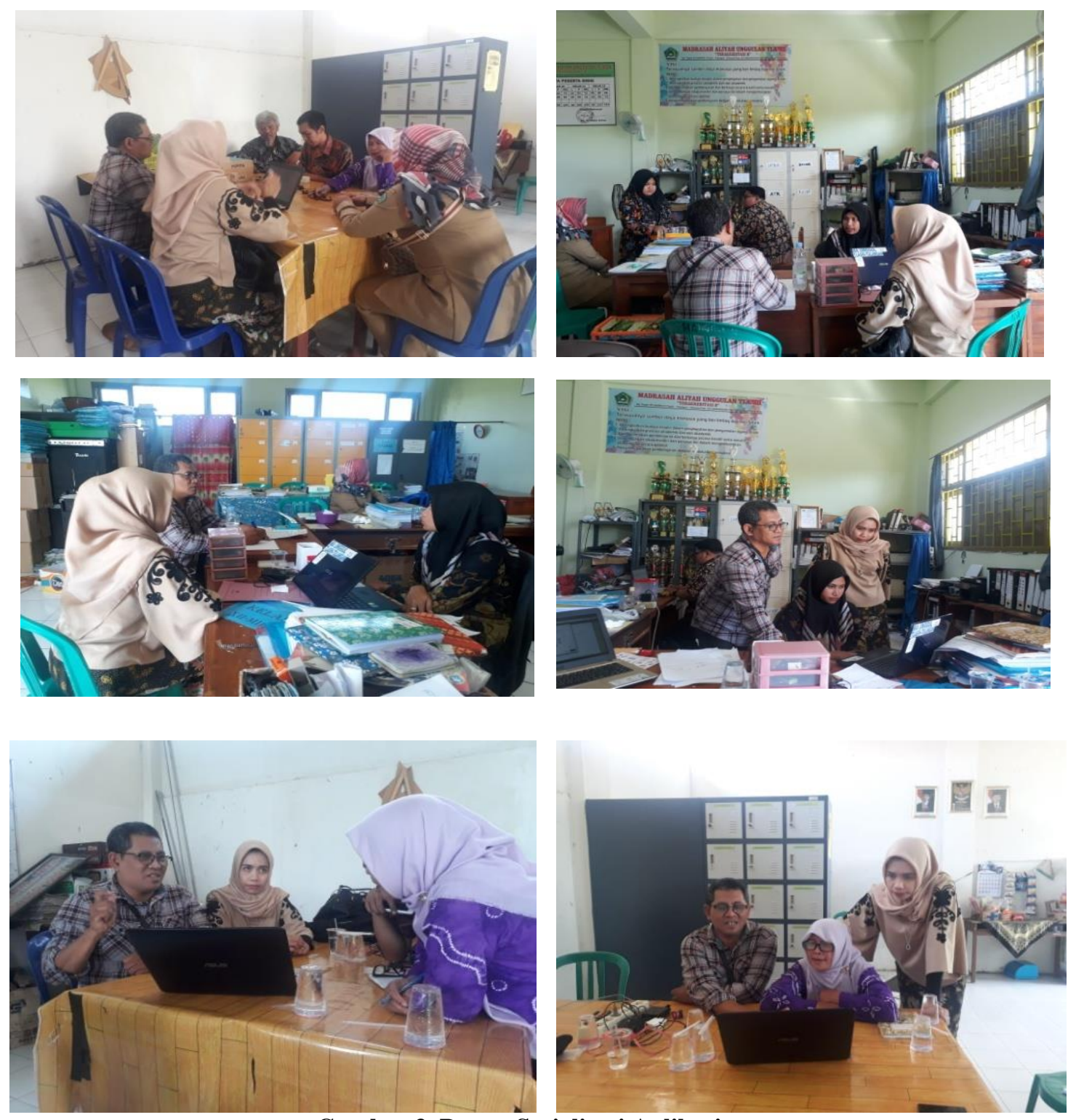

Gambar 3. Proses Sosialisasi Aplikasi

\section{KESIMPULAN}

1. Obyek abdimas sangat antusias dalam menerima masukan-masukan dari kegiatan ini, karena dengan adanya kegiatan ini dapat membantu mereka dalam mengelola manajemen keuangan sekolah yang sebelumnya dilakukan dengan sangat sederhana

2. Kegiatan abdimas ini juga menjadi sharing ilmu bagi pihak sekolah khususnya bendahara dan kepala sekolah bagaimana sebaiknya akuntansi keuangan sekolah dengan berbasis Web

3. Untuk selanjutnya, dari tim abdimas akan melakukan pengembangan dari sebelumnya, yaitu sosialisasi dan mengadakan workshop bih lanjut tentang penataan pelaporan keuangan akuntansi sekolah, sehingga aplikasi ini dapat dikembangkan tidak hanya sebatas akuntansi kas, namun dapat sampai dengan menghasilkan output berupa laporan keuangan.

\section{DAFTAR PUSTAKA}

Costa., V. P. (2000). Panduan Pelatihan untuk Mengembangkan Madrasah. Jakarta: Depdiknas.

Setiawati, L., \& Diana, A. (2011). Sistem Informasi Akuntansi, Perancangan, Proses dan Penerapan. Yogyakarta: Andi Yogyakarta. 